\title{
Fabrication of Hollow Silica Particles Using a Self-Assembled Polyethylene Granule as a Template
}

\author{
Sang-Yul Park, Hyo-Sun Kim, Jeseung Yoo, and Young-Soo Seo $\mathbb{D}$ \\ Nanotechnology and Advanced Materials Engineering, Sejong Polymer Research Center, Sejong University, \\ Seoul 143-747, Republic of Korea \\ Correspondence should be addressed to Young-Soo Seo; ysseo@sejong.ac.kr
}

Received 12 March 2018; Accepted 7 May 2018; Published 4 June 2018

Academic Editor: Miguel A. Correa-Duarte

Copyright (C) 2018 Sang-Yul Park et al. This is an open access article distributed under the Creative Commons Attribution License, which permits unrestricted use, distribution, and reproduction in any medium, provided the original work is properly cited.

\begin{abstract}
We developed a novel method preparing nonspherical hollow silica particles (HSP) using a micron-sized granule self-assembled from partially oxidized PE wax. The morphology of the granule was closely investigated in terms of concentration and acid value of PE wax and cooling rate. Due to the oxidized unit in PE wax, magnetic nanoparticle was incorporated into the granule during the self-assembly, and silica was coated on the granule surface via the self-assembly. Silica-coating condition was studied by varying water content and reaction time. After the PE wax was removed by calcination, nonspherical HSP or magnetic HSP was obtained. This cost-effective HSP is expected to be useful for practical applications.
\end{abstract}

\section{Introduction}

Hollow particle (HP) which is defined as a particle with an internal void has received much attention because it is useful in various fields such as lithium battery [1], piezoelectric transducer [2], drug delivery [3-5], catalyst $[6,7]$, and light diffuser [8]. A variety of inorganic materials such as silica $[9,10]$, calcium carbonate [11], copper oxide [12], tin oxide [13], and titanium oxide [14] have been used for building blocks for HP.

Spherical HP has been fabricated via oil-in-water emulsion [15-18], hydrothermal synthesis [19], and self-assembly techniques [20] using a template soft enough having spherical morphology to minimize interfacial energy. By comparison, nonspherical HP was fabricated using an anisotropically grown or clustered structure as a template. For example, hematite $\left(\alpha-\mathrm{Fe}_{2} \mathrm{O}_{3}\right)$ synthesized in various morphologies such as spindle, cube, rod, ellipsoidal, peanut-like, and polyhedron was frequently used as an inorganic template [21-24], and polystyrene colloid clusters having polyhedral structures were used as an organic template [25]. Nonspherical shape is favorable for enhanced physicochemical properties mainly due to a higher specific surface area compared to a spherical one. Nonspherical titanium oxide [14] and NiS HP [26] showed outstanding properties such as a high specific capacitance and good cycling stability.

Considering practical applications of HP, there are some requirements in the template formation as for cost-effective HP fabrication. Surface of either inorganic or organic template should be suitable for inorganic coating usually based on sol-gel reaction. Otherwise, additional surface treatments need to be done in advance. For example, carbon nanotube template for preparing hematite hollow nanohorns needs strong acid treatments for creating surface-active groups [27]. For surface activation, PS colloid was prepared from polymerization of PS monomer mixing with a silane coupling agent [28] or PS colloid was treated by ammonia [29].

Another consideration is the efficiency of template removal. In most cases, template removal is required for creating vacancy inside, which can be done by processes such as calcination and solvent and acid washing. Usually, organic templates are easily removed by calcination in air or solvent washing while inorganic templates such as hematite require strong acid washing. It seems that calcination process is more cost-effective.

Self-assembly process of polyethylene (PE) crystallization has been known since the 1960s [30]. Spherulite structure with few tens micron in size can be obtained from its melt state by a 
TABle 1: Physical properties of polyethylene waxes used.

\begin{tabular}{lcccc}
\hline Properties & Unit & RC1 & RC2 & RC3 \\
\hline Acid value & $(\mathrm{mg} \mathrm{KOH} / \mathrm{g})$ & 0 & $\sim 3.0$ & $\sim 17$ \\
Density $\left(23^{\circ} \mathrm{C}\right)$ & $\left(\mathrm{g} / \mathrm{cm}^{2}\right)$ & $0.96 \sim 0.98$ & $0.96 \sim 0.98$ & $0.97 \sim 0.99$ \\
Drop point & $\left({ }^{\circ} \mathrm{C}\right)$ & $122 \sim 127$ & $122 \sim 127$ & $120 \sim 125$ \\
\hline
\end{tabular}

cooling process which originated from stacking of lamellae with interlamellar thickness of $\sim 12 \mathrm{~nm}$ [31]. Single lamella was obtained from cooling of hot and dilute PE in various solvents [32]. Recently, we found that PE wax could form micronsized ellipsoidal granule composed of multilamellae from a concentrated solution by controlling a cooling rate [33].

In this work, we have proposed a novel approach to synthesize HSP using ellipsoidal PE granule as a template. We fabricated uniform micron-sized and nonspherical PE granule via self-assembly of partially oxidized PE wax in solution, which was successively coated by silica based on a sol-gel reaction without additional surface treatments. By calcination, nonspherical HSP was obtained. It is believed that this is the most cost-effective way to prepare nonspherical HSP. Furthermore, magnetite nanoparticle was incorporated in the granule during the self-assembly so that the resulting HSP is capable of being attracted to the magnet. As a potential application, efficient removal of toxic chemical from the waste water was demonstrated.

\section{Experimentals}

2.1. Materials. Three kinds of PE wax with different acid values were used for fabricating templates. According to the acid value, PE waxes were named as $\mathrm{RC} 1(0 \mathrm{mg} \mathrm{KOH} / \mathrm{g})$, RC2 ( $3 \mathrm{mg} \mathrm{KOH} / \mathrm{g})$, and RC3 ( $17 \mathrm{mg} \mathrm{KOH} / \mathrm{g})$. In Table 1, the physical properties of each PE wax are summarized. We purchased tetraethyl orthosilicate (TEOS, 98\%, reagent grade), toluene (HPLC grade), ammonia solution (28\%), $\mathrm{Fe}_{3} \mathrm{O}_{4}$ nanoparticles, and anhydrous ethanol from SigmaAldrich Korea.

2.2. Ellipsoidal HSP Formation. PE wax was mixed with toluene and heated at about $100^{\circ} \mathrm{C}$ until the solution become clear. Then, the solution was cooled down to room temperature with a controlled cooling rate using a water bath. PE granule was collected by centrifugation at $6000 \mathrm{rpm}$ for $10 \mathrm{~min}$ and washed 3 times using ethanol. Silica coating was done via a sol-gel method known as a Stöber method [34]. The PE granule was dispersed in ethanol, and then TEOS, deionized water, and ammonia solution were successively added while mild stirring at room temperature. After the reaction, the silica-coated $\mathrm{PE}$ granule was washed 3 times with ethanol and dried. To obtain HSP, PE granule was calcinated at $500^{\circ} \mathrm{C}$ for $2 \mathrm{hr}$.

2.3. Characterization. Wide-angle X-ray diffraction (WAXD) and small-angle X-ray scattering (SAXS) measurements were conducted at PLS-II 9A U-SAXS beamline of Pohang Accelerator Laboratory (PAL) in Korea. Diffraction angles were calibrated by a precalibrated sucrose [35]. And the sample- to-detector distance was about $225 \mathrm{~mm}$ and $2.5 \mathrm{~m}$ for WAXD and SAXS, respectively. The X-ray wavelength was $0.6218 \AA$. WAXD and SAXS patterns were recorded with a $2 \mathrm{D}$ CCD detector (Rayonix SX165), and X-ray irradiation time was few seconds dependent on the saturation level of detector.

\section{Results and Discussion}

\subsection{Morphology of Micron-Sized PE Granule}

3.1.1. Acid Value of PE Wax. Even though the morphology of single lamella has been extensively studied from the dilute solution and the melt $[31,32]$, self-assembly of PE wax having broad molecular weight distribution from a nondilute solution has been rarely studied, in particular, not for partially oxidized PE wax. The oxidation degree of PE wax can be defined by acid value where PE wax possesses oxygencontaining functional groups such as carboxyl, hydroxyl, and carbonyl, expecting reduction in crystallinity of selfassembled structures.

As shown in Figure 1(a), the hexagonal-shaped granule was formed from $\mathrm{RC} 1$ solution where the concentration and cooling rate were $1.0 \mathrm{wt} \%$ and $10^{\circ} \mathrm{C} / \mathrm{min}$, respectively. The dimension of the granule was found to be few hundred $\mathrm{nm}$ in thickness and $2-3 \mu \mathrm{m}$ in size, indicating that hundreds of single lamella with $\sim 12 \mathrm{~nm}$ in thickness were stacked to form multilamellar structure due to strong van der Waals interaction between lamellae [33]. It is noted that this crystallization and stacking process takes only few minutes. As the acid value increases, the granule shape became more rounded and ellipsoidal as shown in Figures 1(b) and 1(c).

WAXD spectrum of each granule is shown in Figure 1(d). There are two characteristic peaks of PE granule corresponding to 110 and 200 which moved toward a lower angle as the acid value increases, meaning larger interspacing. From the peak area, the crystallinity of each $\mathrm{PE}$ granule also was calculated, which is $79.2 \%$ for RC1, $74.6 \%$ for RC2, and $68.2 \%$ for RC3, respectively. As expected, the crystallinity decreases as the acid value increases.

The SAXS spectra and 2D scattering images of each PE template are shown in Figure 1(e). Interlamellar distance of the PE granule was calculated to $11.3 \mathrm{~nm}(\mathrm{RC} 1), 10.8 \mathrm{~nm}$ (RC2), and $10.3 \mathrm{~nm}$ (RC3) using Bragg's law, which became thinner as the acid value increased.

Silica coating has been done on each granule using a solgel method. As shown in the inset of Figures 1(a)-1(c), there was no silica formed on RC1 granule surface, and silica particles were sparsely attached on RC2 while on RC3 granule surface silica, silica particles are densely covered. As expected, RC1 having 0 acid value was not able to be a template for silica coating because the surface has a very low 


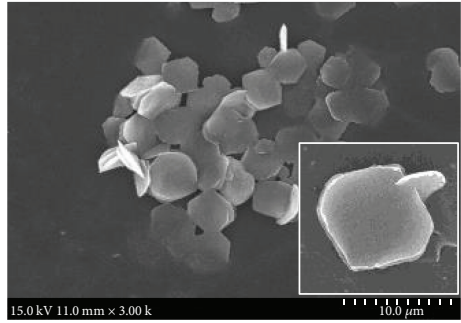

(a)

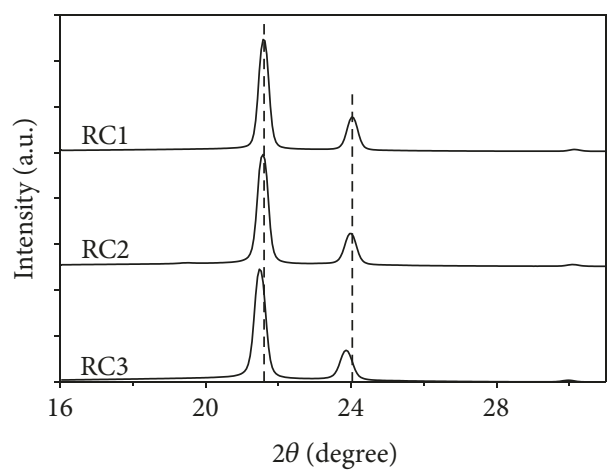

(b)

(d)

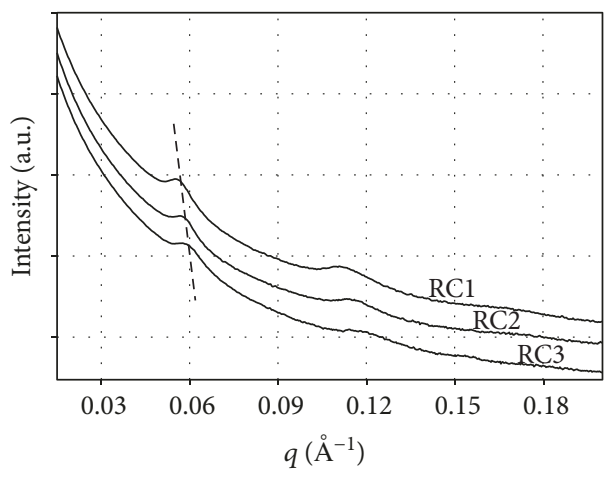

(e)
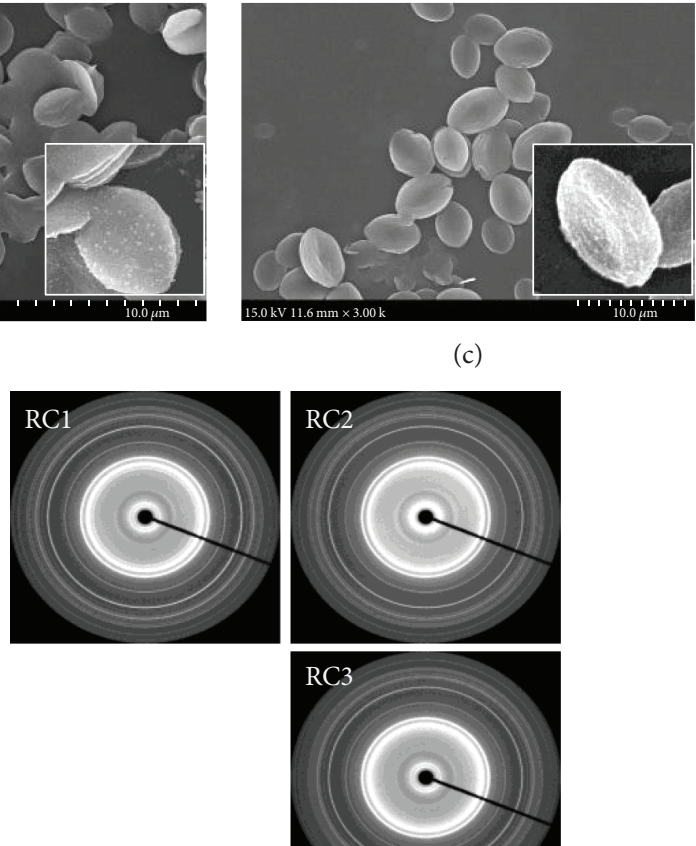

(c)
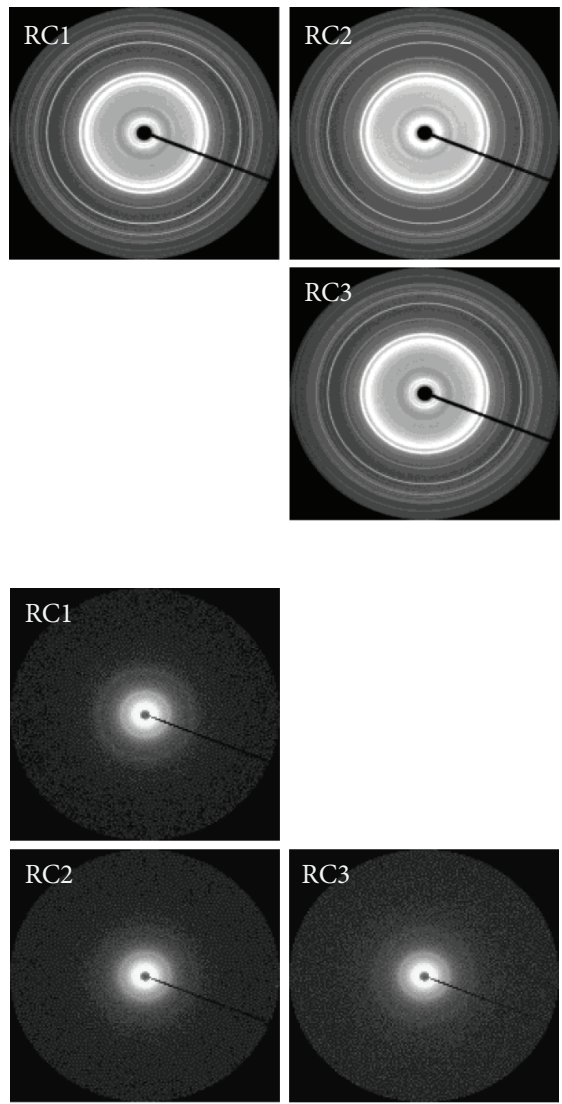

Figure 1: SEM images of the granule from (a) RC1, (b) RC2, and (c) RC3. (d) WAXD and (e) SAXS pattern and its corresponding 2D diffraction images of each crystal. The concentration and cooling rate for crystal formation were fixed at 1.0 wt $\%$ and $10^{\circ} \mathrm{C} / \mathrm{min}$, respectively. Insets in (a)-(c) show the silica-coated granules.

surface tension, that is, no polarity. As a template for HSP, the surface should be adequate for silica coating based on a sol-gel process. The granule prepared from PE wax with certain acid value can be a template for silica coating on which oxygen-containing groups exist to be served as active surface that can be wetted by TEOS. From now on, we focused on RC3 for fabricating HSP.

3.1.2. Concentration. The morphology of the self-assembled granule should be dependent on PE wax concentration. Figures 2(a) and 2(b) show the SEM images of granules self-assembled from RC3 with a concentration of $0.1,1.0$, 2.0 , and $3.0 \mathrm{wt} \%$. The cooling rate was fixed at $10^{\circ} \mathrm{C} / \mathrm{min}$. The average size of the granule increased from 1.8 to $7.5 \mu \mathrm{m}$ as the concentration of solution increased. And average thickness of the granule was measured to $\sim 100 \mathrm{~nm}$, $\sim 0.7 \mu \mathrm{m}, \sim 2.0 \mu \mathrm{m}$, and $\sim 4.0 \mu \mathrm{m}$, respectively.

In the figure, we clearly see that the granule is composed of many plies, indicating that a single lamella stacks face-toface to form the granule. From the interlamellar spacing obtained from SAXS, the granule is composed of $\sim 60$ lamellae in case of $1.0 \mathrm{wt} \%$. It is noted that lamellar stacking is faster on the edge of a granule at high concentrations, resulting in a recessed structure in the center.

3.1.3. Cooling Rate. Cooling rate is also an important factor to control granule morphology. Figures $2(\mathrm{e})-2(\mathrm{~h})$ show the SEM images of the RC3 granule with a cooling rate of $\sim 150, \sim 15, \sim 7$, and $\sim 3^{\circ} \mathrm{C} / \mathrm{min}$, respectively. In case of a fast cooling rate of $150^{\circ} \mathrm{C} / \mathrm{min}$, thin and flexible granule was formed. As the 


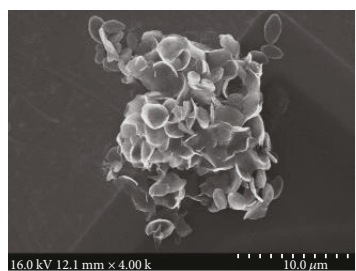

(a)

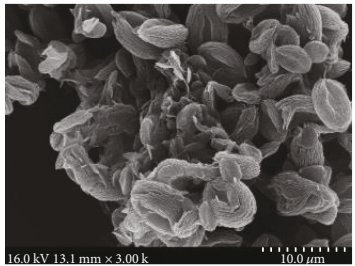

(d)

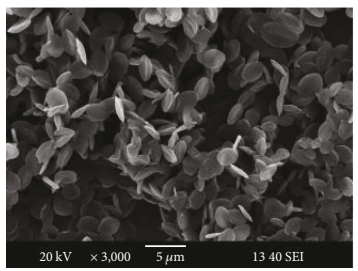

(f)

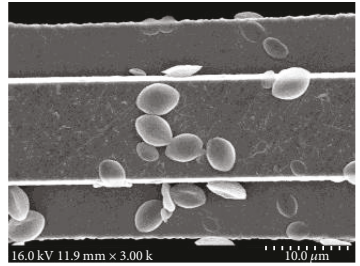

(b)

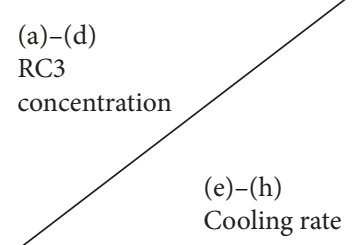

Cooling rate

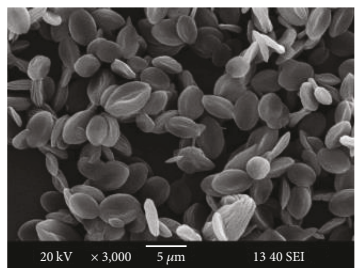

$(\mathrm{g})$

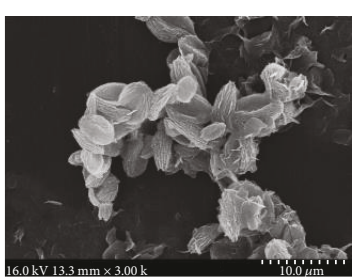

(c)

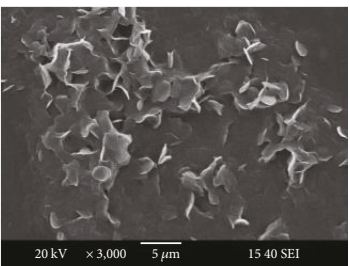

(e)

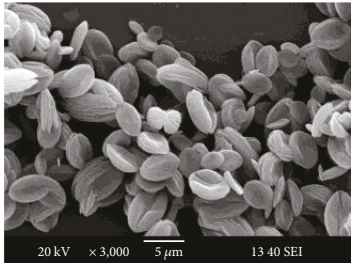

(h)

Figure 2: SEM images of the RC3 granule as a function of the concentration of solution (a) 0.1, (b) 1.0 , (c) 2.0 , and (d) $3.0 \mathrm{wt} \%$ and as a function of the cooling rate of (e) $\sim 150$, (f) $\sim 15$, (g) $\sim 7$, and $(\mathrm{h}) \sim 3^{\circ} \mathrm{C} / \mathrm{min}$.
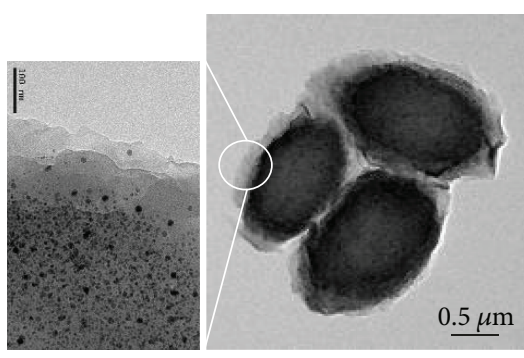

(a)

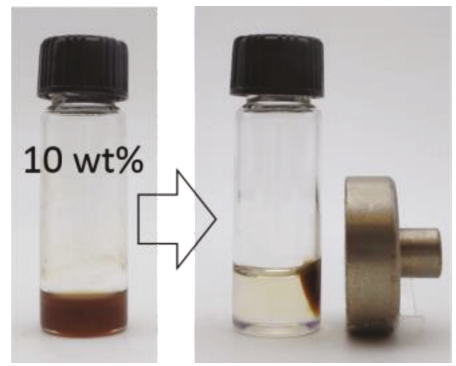

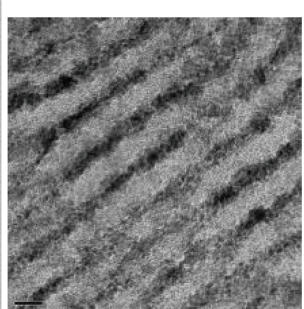

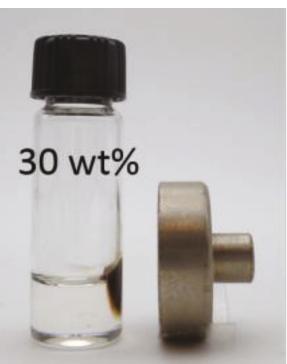

(c)

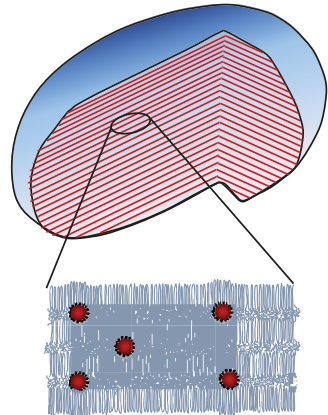

(b)

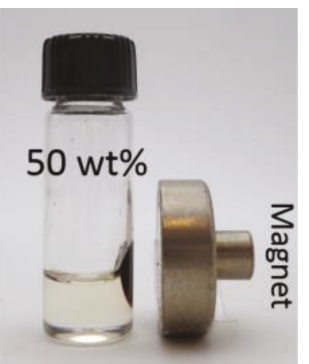

Figure 3: TEM images of (a) $30 \mathrm{wt} \% \mathrm{Fe}_{3} \mathrm{O}_{4}$ nanoparticle entrapped PE wax granule and its cross-sectional view. (b) Schematic diagram for $\mathrm{Fe}_{3} \mathrm{O}_{4}$ nanoparticle entrapped between lamellae. (c) 10, 30, and $50 \mathrm{wt} \% \mathrm{Fe}_{3} \mathrm{O}_{4}$ nanoparticle entrapped $\mathrm{PE}$ granule in toluene solution before and after the magnetic field was applied.

cooling rate decreased, the granule size became bigger. From the WAXD spectrum, crystallinity of a granule was measured to $71.5 \%$ and $64.2 \%$ for $\sim 3$ and $\sim 15^{\circ} \mathrm{C} / \mathrm{min}$ of cooling rate, respectively, indicating that a slower cooling rate induced not only bigger crystal but also higher crystallinity.
The slower cooling rate effect on the granule morphology was similar to the higher concentration. However, it seems that controlling the cooling rate provided more regularity and reproducibility in regulating granule morphology than concentration. Therefore, the experimental condition for 


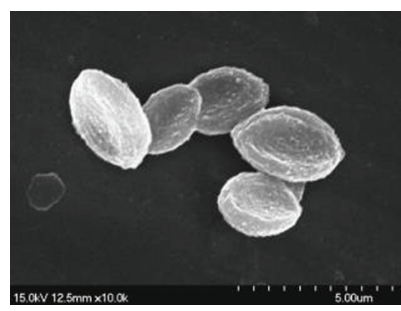

(a)

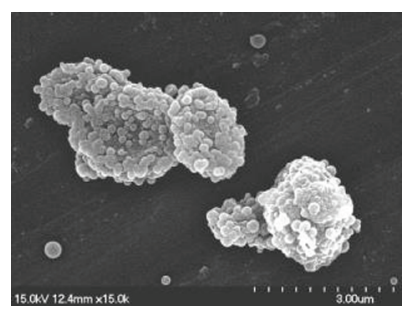

(c)

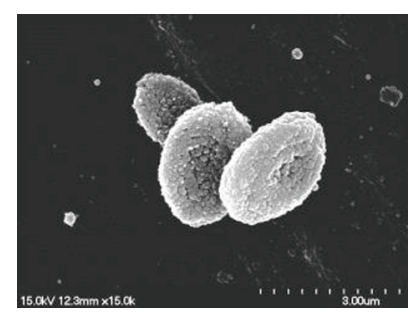

(b)

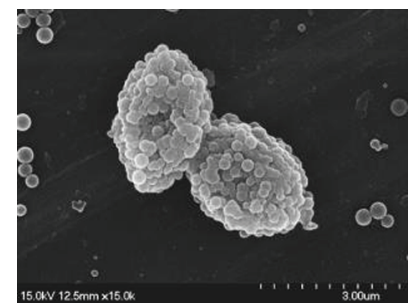

(d)

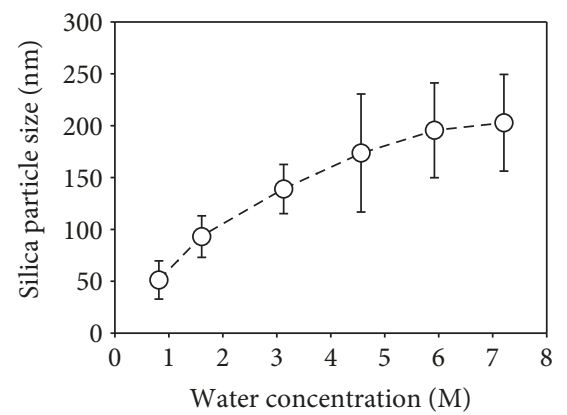

(e)

FIGURE 4: SEM images of silica-coated RC3 template as a function of water concentration of (a) 0.82 M, (b) 3.1 M, (c) 5.9 M, and (d) 7.2 M. (e) Silica particle size is displayed according to water concentration.

granule formation using RC3 was chosen to be a concentration of $1.0 \mathrm{wt} \%$ with a cooling rate of $10^{\circ} \mathrm{C} / \mathrm{min}$, which will be applied for HSP fabrication.

3.1.4. Magnetite Nanoparticle Trapping. During the multilamellar self-assembly, quantum dot can be trapped in between lamellae [33]. Here, magnetite nanoparticle $\left(\mathrm{Fe}_{3} \mathrm{O}_{4}\right.$, diameter $20 \mathrm{~nm}$ ) was added when PE wax granule was selfassembled. Figure 3(a) shows that the particles (30 wt $\%$ based on $\mathrm{PE}$ amount) are trapped inside the ellipsoidal granule and evenly distributed. The cross-sectional TEM image (thickness of the slice for the TEM sample was about $100 \mathrm{~nm}$ ) on the right provided that the particles exist only in between the lamellae, implying that the nanoparticle was entrapped after the single lamella formation depicted as Figure 3(b). After the self-assembly, the solution was centrifuged to get granules, and the supernatant was found to be clear, confirming that all the particles were trapped in the granule during the self-assembly. We found that PE wax with no acid value (RC1) could not trap any particle inside, which indicates that entrapping nanoparticles is mainly due to polar interaction between oxygen-containing functional groups on the lamella and the nanoparticle. Figure 3(c) shows 10, 30, and $50 \mathrm{wt} \%$ magnetite nanoparticle trapped granules in toluene solution, and all the granules were attracted to a magnet.

\subsection{Hollow Silica Particle (HSP) Formation}

3.2.1. Water Concentration. The morphology of silica particles based on the sol-gel method was affected by various factors such as the precursor, catalyst, reaction time, and reaction temperature. Water content is important for initiating hydrolysis determining the initial reaction rate and condensation kinetics, which is related to silica colloid size in the reaction [36]. A granule made from RC3 dispersed in ethanol was used for silica coating. The reaction condition was that the concentration of TEOS, ammonia, and reaction time was fixed to $0.3 \mathrm{M}, 1.0 \mathrm{M}$, and $2 \mathrm{hr}$, respectively, while the concentration of water changed from 0.82 to $7.2 \mathrm{M}$. By observation, the reaction solution became opaque within a few minutes for water content of greater than $2.2 \mathrm{M}$ while for the lowest water concentrations, turbid solution started to appear after an hour. Therefore, a reaction time of $2 \mathrm{hr}$ was chosen to consume TEOS as much as possible for finding water effect.

From the SEM image of silica-coated granule in Figures 4(a)-4(d), silica particle was uniformly coated and grew on the surface of the granule. Silica particle size on the granule was measured from the SEM images and displayed 


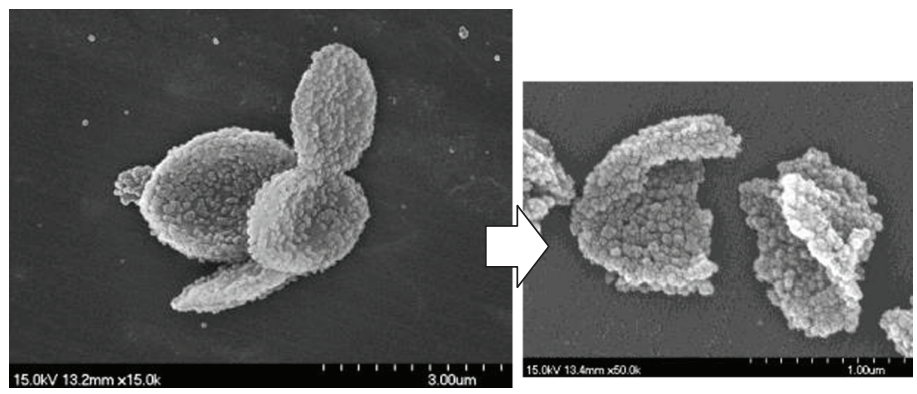

(a)

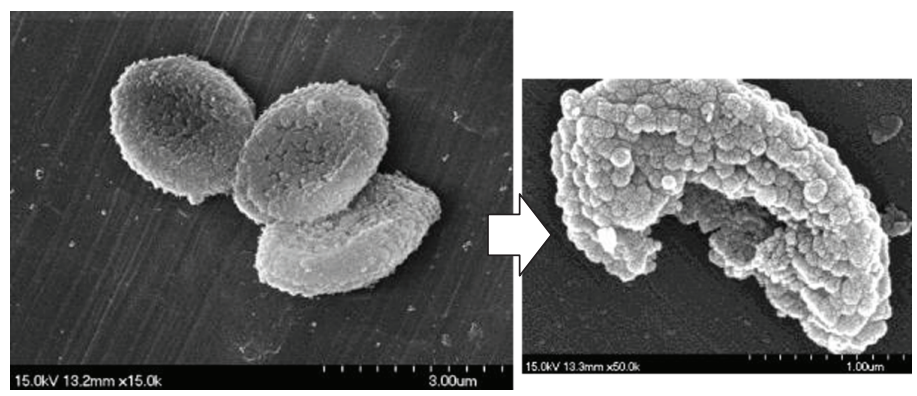

(b)

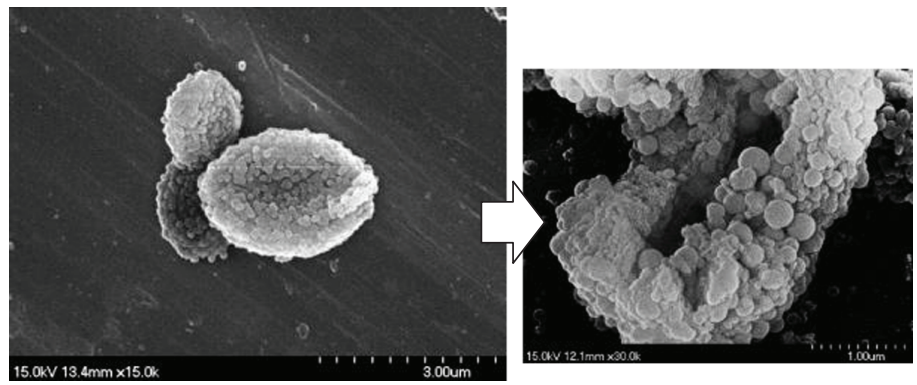

(c)

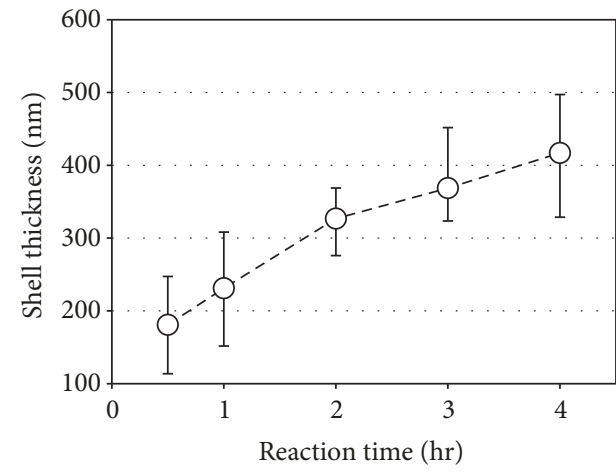

(d)

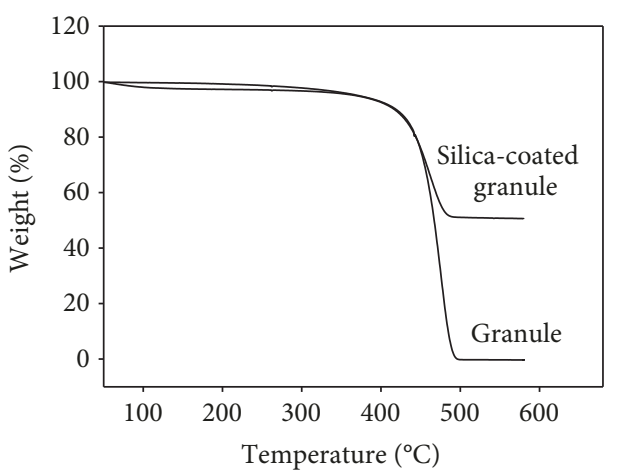

(e)

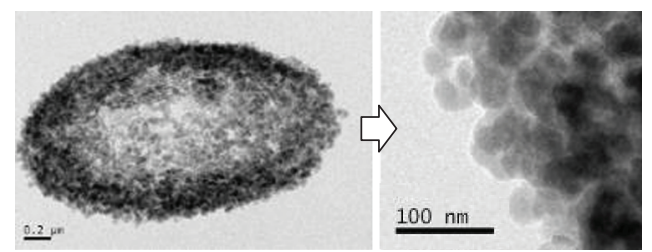

(f)

FIGURE 5: SEM images of silica-coated granules according to a reaction time of (a) $0.5 \mathrm{hr}$, (b) $2 \mathrm{hr}$, and (c) $4 \mathrm{hr}$ and broken pieces after calcination in the inset. (d) Shell thickness obtained from (c). (e) TGA thermograms of the RC3 granule and silica-coated RC3 granule. (f) TEM image of HSP calcinated at $500^{\circ} \mathrm{C}$ for $2 \mathrm{hr}$ in air condition. 

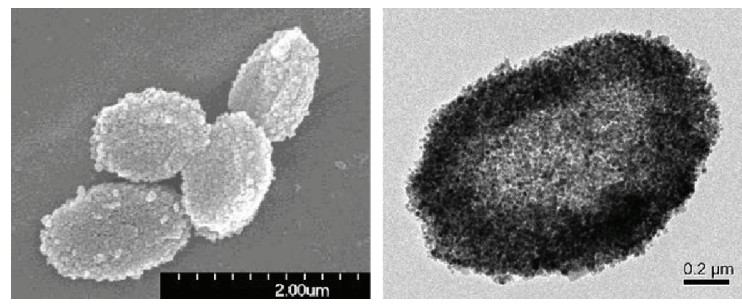

(a)

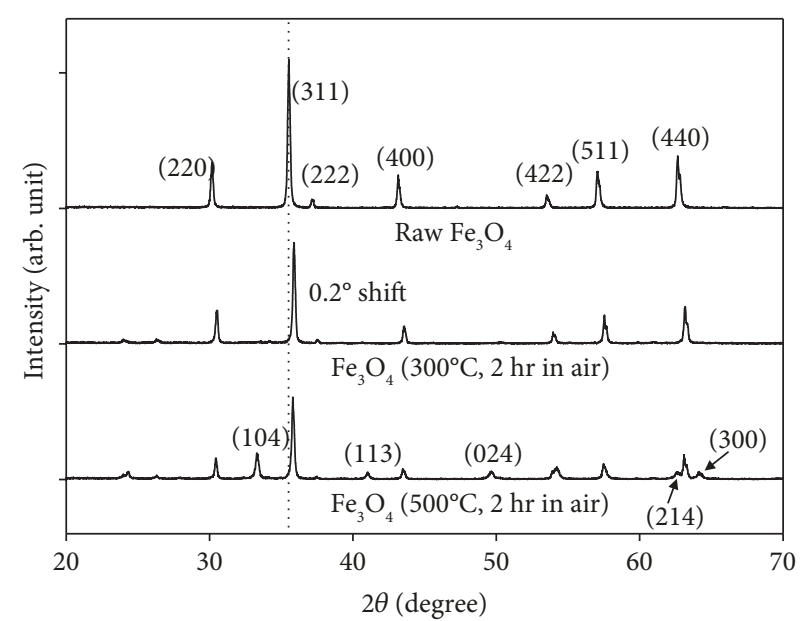

(b)

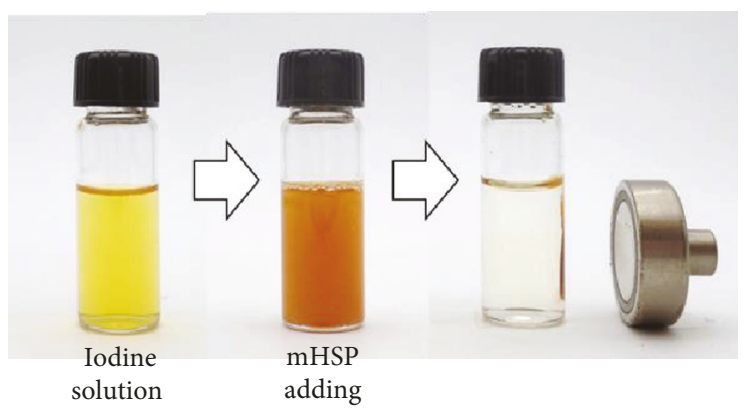

(c)

Figure 6: (a) SEM and TEM images of silica-coated RC3 granule incorporated with $\mathrm{Fe}_{3} \mathrm{O}_{4}$ nanoparticle after calcination at $500^{\circ} \mathrm{C}$ for $2 \mathrm{hr}$. (b) XRD spectra of $50 \mathrm{~nm} \mathrm{Fe}_{3} \mathrm{O}_{4}$ nanoparticle before and after heat treatment in air. (c) mHSP separation by a magnet after iodine absorption from the iodine contaminated water.

in Figure $4(\mathrm{e})$ as a function of water concentration. It increased with water content where the size was $\sim 50 \mathrm{~nm}$ at $0.82 \mathrm{M}$ water and reached $\sim 200 \mathrm{~nm}$ at $7.2 \mathrm{M}$. This behavior is similar to colloidal silica particle growth in terms of water concentration [37].

3.2.2. Effect of Reaction Time. The effect of the sol-gel reaction time on the morphology of silica was also monitored. The reaction time was controlled from $0.5 \mathrm{hr}$ to $4 \mathrm{hr}$ while the concentration of TEOS, ammonia, and deionized water was fixed at $0.13 \mathrm{M}, 1.0 \mathrm{M}$, and $3.1 \mathrm{M}$, respectively. Figures 5(a)-5(c) showed the SEM pictures of silica-coated granule and, after calcination, broken pieces of hollow silica particle (HSP) which was deliberately broken to check silica-coating thickness, $d$. Figure $5(\mathrm{~d})$ summarized $d$ as a function of the reaction time. At $0.5 \mathrm{hr}, \sim 50 \mathrm{~nm}$ silica particle was coated on the surface and $d$ of HSP was found to be $\sim 190 \mathrm{~nm}$. For 2 and $4 \mathrm{hr}, d$ was $\sim 320 \mathrm{~nm}$ and $\sim 410 \mathrm{~nm}$, and the particle size on the surface was getting bigger while smaller particles are still found underneath. In summary, silica coating on the granule underwent a process in which small particles grew on the surface and bigger particles grew on the next layer as the reaction time, in which behavior is similar to colloidal silica growth mechanism as previously reported [38].
3.2.3. Calcination. Figure 5(e) showed the TGA thermograms of the RC3 granule with and without silica coating where silica-coating condition was fixed to be at a concentration of TEOS, ammonia, and deionized water and reaction time of $0.13 \mathrm{M}, 1.0 \mathrm{M}, 2.0 \mathrm{M}$, and $2 \mathrm{hr}$, respectively. The granule started to lose weight at $400^{\circ} \mathrm{C}$ and was totally removed at $500^{\circ} \mathrm{C}$ while the silica-coated granule left its weight in half, indicating that coated silica amount is similar to the granule weight. Therefore, calcination condition to prepare HSP was fixed to $500^{\circ} \mathrm{C}$ for $2 \mathrm{hr}$ in the air environment, which was applied to the samples in Figures 5(a)-5(c). TEM image of the HSP is shown in Figure 5(f) where it is confirmed that a hollow space exists inside and $40-70 \mathrm{~nm}$ silica particles are densely packed on the surface.

3.2.4. Magnetic HSP ( $m H S P$ ). Figure 6(a) shows the SEM and TEM images of silica-coated magnetite nanoparticle trapped RC3 granule after calcination. From the TEM image, it is found that the nanoparticle was thoroughly adsorbed in the silica shell instead of cluster formation. The calcination process could induce to transform $\mathrm{Fe}_{3} \mathrm{O}_{4}$ (magnetite) to $\alpha$ - $\mathrm{Fe}_{2} \mathrm{O}_{3}$ (hematite) or $\gamma-\mathrm{Fe}_{2} \mathrm{O}_{3}$ (maghemite) [39]. We checked the $\mathrm{Fe}_{3} \mathrm{O}_{4}$ particle crystal structure using XRD after annealing as shown in Figure 6(b). Here, $50 \mathrm{~nm} \mathrm{Fe}{ }_{3} \mathrm{O}_{4}$ particle was used. After annealing at $300^{\circ} \mathrm{C}$ for $2 \mathrm{hr}$, all the peaks were shifted to 
$0.2^{\circ}$ to the right indicating that most of the magnetite phases seemed to be transformed into maghemite because both crystals have the same spinel ferrite structure with slightly different spacing. After annealing at $500^{\circ} \mathrm{C}$ for $2 \mathrm{hr}$ (calcination condition for removing PE granule), XRD peaks indicated that there was almost no magnetite left in the sample, transforming to hematite and maghemite mixtures. This HSP incorporated with hematite and maghemite nanoparticles is called magnetic HSP (or mHSP).

As one of the HSP applications, removal of toxic chemical such as iodine contaminated in water has been suggested [40]. We duplicated the iodine removal test according to the reference using mHSP. Figure 6(c) shows that iodine in the water phase was transferred to butyl acetate phase filled with mHSP, and then the mHSP was easily separated by attaching a magnet. Therefore, this magnetically attractable HSP could be useful for toxic chemical removals.

\section{Conclusion}

In this work, we have proposed a novel method to synthesize hollow silica particles (HSP) using a polyethylene granule as a template for silica shell. We fabricated micron-sized and nonspherical PE polyethylene granule via self-assembly of partially oxidized PE wax, which was successively coated by silica based on a sol-gel reaction without additional surface treatments. Furthermore, magnetite nanoparticles were entrapped in the granule during the self-assembly so that the resulting HSP was capable of being attracted to the magnet extending its potential applications such as toxic chemical removal from the waste water. It is believed that this process is the most cost-effective way to prepare HSP.

\section{Data Availability}

The data used to support the findings of this study are available from the corresponding author upon request.

\section{Conflicts of Interest}

The authors declare that they have no conflicts of interest.

\section{Acknowledgments}

This research was supported by the Technology Innovation Program (Grant no. 10076562) and the Korea Institute of Energy Technology Evaluation and Planning (no. 20164030201340) of the Korean Government's Ministry of Trade, Industry \& Energy.

\section{References}

[1] Z. Wang, L. Zhou, and X. W. David Lou, "Metal oxide hollow nanostructures for lithium-ion batteries," Advanced Materials, vol. 24, no. 14, pp. 1903-1911, 2012.

[2] J. K. Cochran, "Ceramic hollow spheres and their applications," Current Opinion in Solid State and Materials Science, vol. 3, no. 5, pp. 474-479, 1998.

[3] A. M. Chen, M. Zhang, D. Wei et al., "Co-delivery of doxorubicin and Bcl-2 siRNA by mesoporous silica nanoparticles enhances the efficacy of chemotherapy in multidrug-resistant cancer cells," Small, vol. 5, no. 23, pp. 2673-2677, 2009.

[4] M. J. K. Thomas, I. Slipper, A. Walunj et al., "Inclusion of poorly soluble drugs in highly ordered mesoporous silica nanoparticles," International Journal of Pharmaceutics, vol. 387, no. 1-2, pp. 272-277, 2010.

[5] J. L. Vivero-Escoto, I. I. Slowing, C. W. Wu, and V. S. Y. Lin, "Photoinduced intracellular controlled release drug delivery in human cells by gold-capped mesoporous silica nanosphere," Journal of the American Chemical Society, vol. 131, no. 10, pp. 3462-3463, 2009.

[6] S. Zhang, J. Wang, and X. Wang, "Effect of calcination temperature on structure and performance of $\mathrm{Ni} / \mathrm{TiO}_{2}-\mathrm{SiO}_{2}$ catalyst for $\mathrm{CO}_{2}$ reforming of methane," Journal of Natural Gas Chemistry, vol. 17, no. 2, pp. 179-183, 2008.

[7] S. Zhang, J. Wang, H. Liu, and X. Wang, "One-pot synthesis of Ni-nanoparticle-embedded mesoporous titania/silica catalyst and its application for $\mathrm{CO}_{2}$-reforming of methane," Catalysis Communications, vol. 9, no. 6, pp. 995-1000, 2008.

[8] W. Suthabanditpong, M. Tani, C. Takai, M. Fuji, R. Buntem, and T. Shirai, "Facile fabrication of light diffuser films based on hollow silica nanoparticles as fillers," Advanced Powder Technology, vol. 27, no. 2, pp. 454-460, 2016.

[9] M. Chen, L. Wu, S. Zhou, and B. You, "A method for the fabrication of monodisperse hollow silica spheres," Advanced Materials, vol. 18, no. 6, pp. 801-806, 2006.

[10] F. Caruso, R. A. Caruso, and H. Möhwald, "Nanoengineering of inorganic and hybrid hollow spheres by colloidal templating," Science, vol. 282, no. 5391, pp. 1111-1114, 1998.

[11] W. Wei, G. H. Ma, G. Hu et al., "Preparation of hierarchical hollow $\mathrm{CaCO}_{3}$ particles and the application as anticancer drug carrier," Journal of the American Chemical Society, vol. 130, no. 47, article 15808, 15810 pages, 2008.

[12] J. G. Lee, R. Nakamura, Y. S. Choi, J. H. Yu, and C. J. Choi, "Formation of hollow copper oxide by oxidation of $\mathrm{Cu}$ nanoparticles," Current Nanoscience, vol. 10, no. 1, pp. 101-103, 2014.

[13] X. W. Lou, Y. Wang, C. Yuan, J. Y. Lee, and L. A. Archer, "Template-free synthesis of $\mathrm{SnO}_{2}$ hollow nanostructures with high lithium storage capacity," Advanced Materials, vol. 18, no. 17, pp. 2325-2329, 2006.

[14] X. W. Lou and L. A. Archer, "A general route to nonspherical anatase $\mathrm{TiO}_{2}$ hollow colloids and magnetic multifunctional particles," Advanced Materials, vol. 20, no. 10, pp. 18531858, 2008.

[15] S. Schacht, Q. Huo, I. G. Voigt-Martin, G. D. Stucky, and F. Schuth, "Oil-water interface templating of mesoporous macroscale structures," Science, vol. 273, no. 5276, pp. 768771, 1996.

[16] M. Jafelicci Jr., M. Rosaly Davolos, F. José dos Santos, and S. José de Andrade, "Hollow silica particles from microemulsion," Journal of Non-Crystalline Solids, vol. 247, no. 1-3, pp. 98-102, 1999.

[17] T. Aubert, F. Grasset, S. Mornet et al., "Functional silica nanoparticles synthesized by water-in-oil microemulsion processes," Journal of Colloid and Interface Science, vol. 341, no. 2, pp. 201-208, 2010.

[18] L. Song, X. Ge, M. Wang, and Z. Zhang, "Direct preparation of silica hollow spheres in a water in oil emulsion system: the effect of $\mathrm{pH}$ and viscosity," Journal of Non-Crystalline Solids, vol. 352, no. 21-22, pp. 2230-2235, 2006. 
[19] Q. Yu, P. Wang, S. Hu, J. Hui, J. Zhuang, and X. Wang, "Hydrothermal synthesis of hollow silica spheres under acidic conditions," Langmuir, vol. 27, no. 11, pp. 71857191, 2011.

[20] F. Caruso, H. Lichtenfeld, M. Giersig, and H. Möhwald, "Electrostatic self-assembly of silica nanoparticle-polyelectrolyte multilayers on polystyrene latex particles," Journal of the American Chemical Society, vol. 120, no. 33, pp. 85238524, 1998.

[21] A. K. Patra, S. K. Kundu, A. Bhaumik, and D. Kim, "Morphology evolution of single-crystalline hematite nanocrystals: magnetically recoverable nanocatalysts for enhanced facet-driven photoredox activity," Nanoscale, vol. 8, no. 1, pp. 365-377, 2016.

[22] S. H. Lee, Y. Song, I. D. Hosein, and C. M. Liddell, "Magnetically responsive and hollow colloids from nonspherical coreshell particles of peanut-like shape," Journal of Materials Chemistry, vol. 19, no. 3, pp. 350-355, 2009.

[23] L. Y. Hao, C. L. Zhu, W. Q. Jiang, C. N. Chen, Y. Hu, and Z. Y. Chen, "Sandwich $\mathrm{Fe}_{2} \mathrm{O}_{3} @ \mathrm{SiO}_{2} @ P P y$ ellipsoidal spheres and four types of hollow capsules by hematite olivary particles," Journal of Materials Chemistry, vol. 14, no. 19, pp. 29292934, 2004.

[24] K. Woo and H. J. Lee, "Synthesis and magnetism of hematite and maghemite nanoparticles," Journal of Magnetism and Magnetic Materials, vol. 272-276, pp. E1155-E1156, 2004.

[25] Y. S. Cho, T. Y. Kim, G. R. Yi, Y. K. Kim, and C. J. Choi, "Fabrication of colloidal clusters of polymer microspheres and nonspherical hollow micro-particles from Pickering emulsions," Bulletin of the Korean Chemical Society, vol. 33, no. 1, pp. 159-166, 2012.

[26] X. Y. Yu, L. Yu, L. Shen, X. Song, H. Chen, and X. W. D. Lou, "General formation of MS ( $\mathrm{M}=\mathrm{Ni}, \mathrm{cu}, \mathrm{Mn})$ box-in-box hollow structures with enhanced pseudocapacitive properties," Advanced Functional Materials, vol. 24, no. 47, pp. 74407446, 2014.

[27] Z. Wang, D. Luan, S. Madhavi, Y. Hu, and X. W. (. D.). Lou, "Assembling carbon-coated $\alpha-\mathrm{Fe}_{2} \mathrm{O}_{3}$ hollow nanohorns on the CNT backbone for superior lithium storage capability," Energy \& Environmental Science, vol. 5, no. 1, pp. 52525256, 2012.

[28] I. Tissot, J. P. Reymond, F. Lefebvre, and E. Bourgeat-Lami, "SiOH-functionalized polystyrene latexes. A step toward the synthesis of hollow silica nanoparticles," Chemistry of Materials, vol. 14, no. 3, pp. 1325-1331, 2002.

[29] P. Wang, D. Chen, and F. Q. Tang, "Preparation of titaniacoated polystyrene particles in mixed solvents by ammonia catalysis," Langmuir, vol. 22, no. 10, pp. 4832-4835, 2006.

[30] J. I. Lauritzen Jr and J. D. Hoffman, "Theory of formation of polymer crystals with folded chains in dilute solution," Journal of Research of the National Bureau of Standards Section APhysics and Chemistry, vol. 64A, no. 1, pp. 73-1681, 1960.

[31] J. D. Hoffman, L. J. Frolen, G. S. Ross, and J. I. Lauritzen, "On the growth rate of spherulites and axialites from the melt in polyethylene fractions: regime I and regime II crystallization," Journal of Research of the National Bureau of Standards Section A-Physics and Chemistry, vol. 79A, no. 6, pp. 671-699, 1975.

[32] A. Toda, M. Okamura, M. Hikosaka, and Y. Nakagawa, "Three-dimensional shape of polyethylene single crystals grown from dilute solutions and from the melt," Polymer, vol. 46 , no. 20 , pp. $8708-8716,2005$.
[33] S.-Y. Park, H.-S. Kim, J. Yoo et al., "Long-term stability of $\mathrm{CdSe} / \mathrm{CdZnS}$ quantum dot encapsulated in a multi-lamellar microcapsule," Nanotechnology, vol. 26, no. 27, article 275602, 2015.

[34] W. Stöber, A. Fink, and E. Bohn, "Controlled growth of monodisperse silica spheres in the micron size range," Journal of Colloid and Interface Science, vol. 26, no. 1, pp. 62-69, 1968.

[35] R. C. Hynes and Y. Le Page, "Sucrose, a convenient test crystal for absolute structures," Journal of Applied Crystallography, vol. 24, no. 4, pp. 352-354, 1991.

[36] K. D. Kim and H. T. Kim, "Formation of silica nanoparticles by hydrolysis of TEOS using a mixed semi-batch/batch method," Journal of Sol-Gel Science and Technology, vol. 25, no. 3, pp. 183-189, 2002.

[37] S. L. Greasley, S. J. Page, S. Sirovica et al., "Controlling particle size in the Stöber process and incorporation of calcium," Journal of Colloid and Interface Science, vol. 469, pp. 213-223, 2016.

[38] V. M. Masalov, N. S. Sukhinina, E. A. Kudrenko, and G. A. Emelchenko, "Mechanism of formation and nanostructure of Stöber silica particles," Nanotechnology, vol. 22, no. 27, article 275718, 2011.

[39] F. Fajaroh, H. Setyawan, A. Nur, and I. W. Lenggoro, “Thermal stability of silica-coated magnetite nanoparticles prepared by an electrochemical method," Advanced Powder Technology, vol. 24, no. 2, pp. 507-511, 2013.

[40] H. Cong, J. Wang, B. Yu, J. Tang, and W. Cui, "Fabrication of monodisperse anisotropic silica hollow microspheres using polymeric cave particles as templates," Journal of Colloid and Interface Science, vol. 411, pp. 41-46, 2013. 


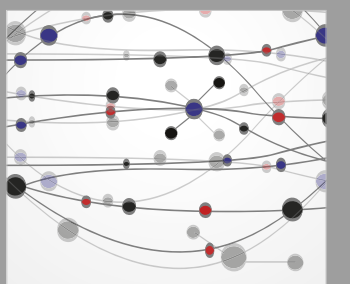

The Scientific World Journal
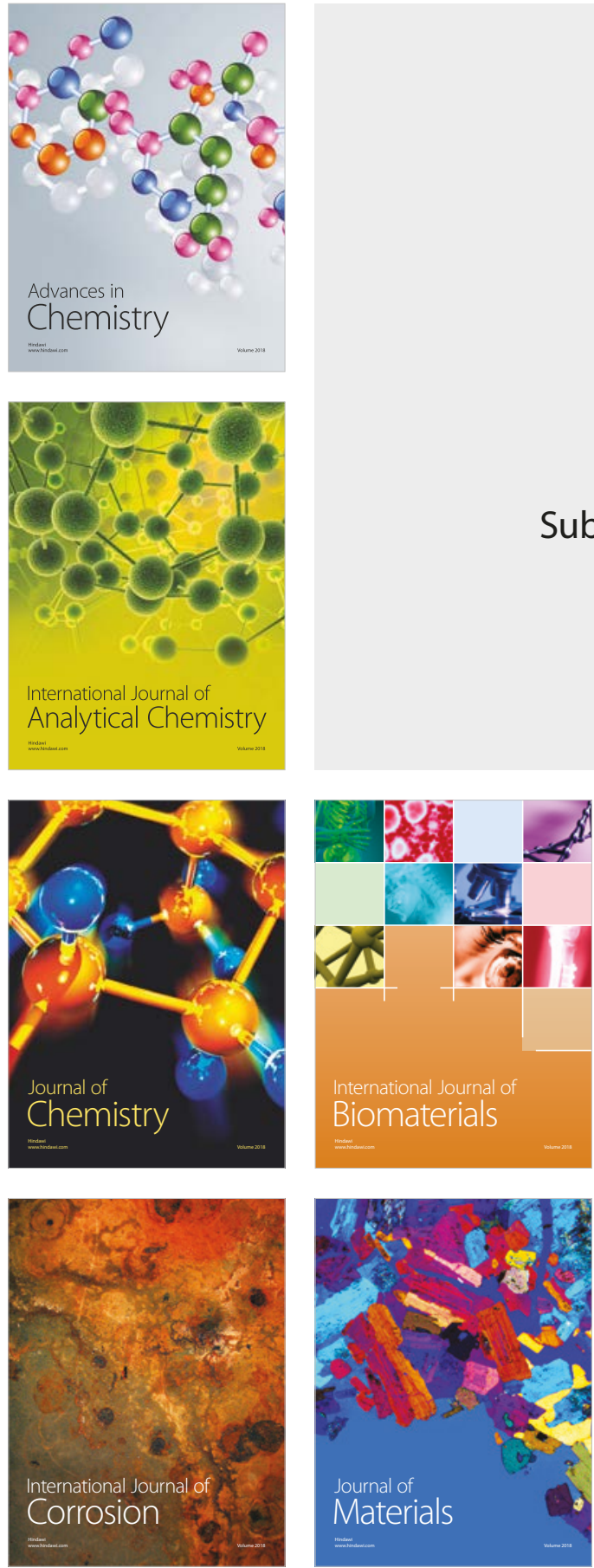

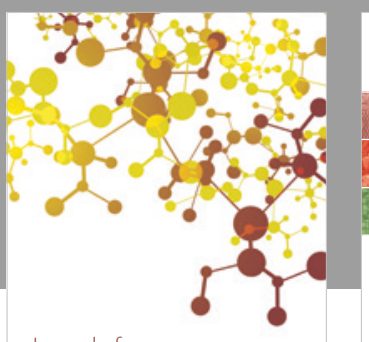

Journal of

Applied Chemistry
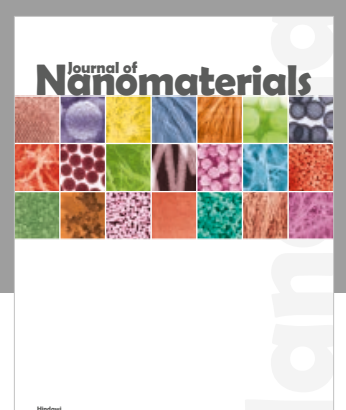

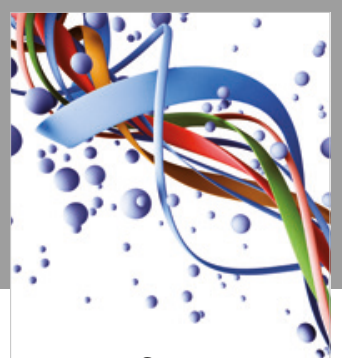

Scientifica

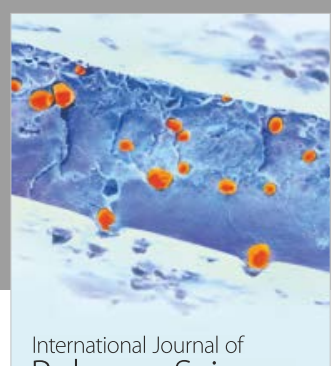

Polymer Science

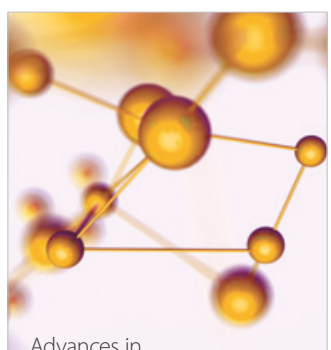

Physical Chemistry
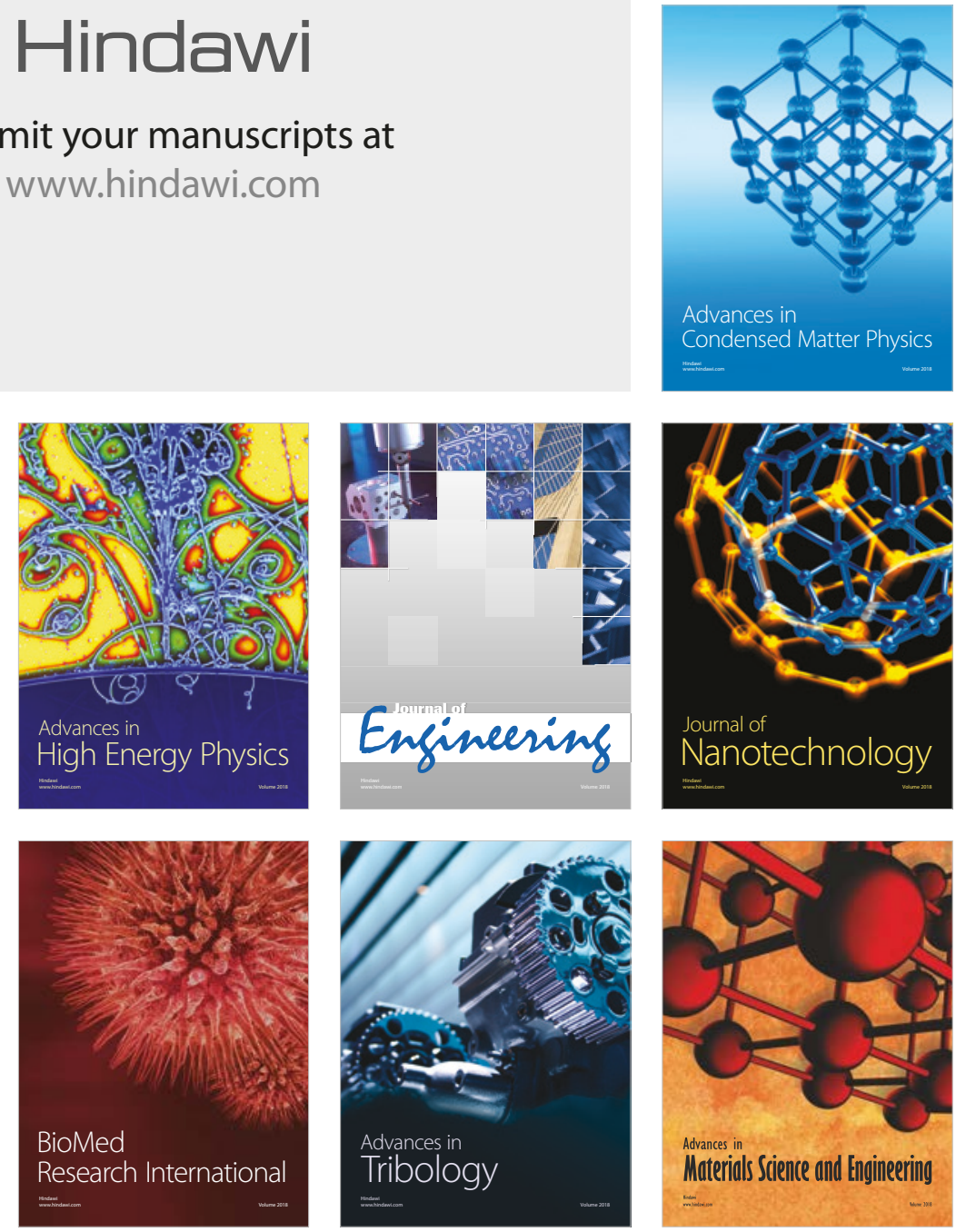